\title{
ISOLASI KUMARIN DARI BIJI PINANG \\ (Areca catechu L.)
}

\author{
Sanusi Ibrahim, Muhamad Iqbal , Bustanul Arifin \\ Jurusan Kimia FMIPA Universitas Andalas
}

\begin{abstract}
Coumarin has been isolated from seed of Areca catechu L. an ethyl acetate fraction which needle crystal products at $184-185^{\circ} \mathrm{C}$. Based on thin layer chromatography analysis using n-hexane : acetone $(4: 6)$ as eluent got Rf 0.6 . From elemental analysis, mass spectra, ultraviolet spectra, infra red spectra, nuclear magnetic resonance spectra ( $\mathrm{H}$ and $\mathrm{C}$ NMR), concluded this compound was 7hidroksi-4-metil coumarine.
\end{abstract}

Keywords : Areca catechu, 7-hidroksi-4-metil kumarin.

\section{DAFTAR PUSTAKA}

1. Ahmad, S. A., 1980, Kimia Organik Bahan Alam, Universitas Terbuka, Jakarta.

2. Arbain, D., 1995, Survey Fitokimia Salah Satu Cara Pendekatan, Proyek HEDS USAID Universitas Andalas, Padang.

3. Cresswell, C.J., 1982, Analisis Spektrum Senyawa Organik, Edisi ke-2, ITB, Bandung.

4. Culvenor, C.C.J., and Fitzgerald, J.L., A field method for alkaloids screening of plants, J.Pharm,Sci., 52: $303-304$.

5. Djamal, R., 1988, Tetumbuhan Sebagai Sumber Bahan Obat, Pusat Penelitian Universitas Andalas, Padang.

6. Murray, R.D.H., 1982, and Brown J., Mendez, The Natural Coumarine, Jhon Willey and Son Ltd. New York.

7. Nordin, et.al., 1985, Aspect of Natural product chemistry, proceeding, the phytochemical survey, Dept. Chemistry, UPM, Malaysia.

8. Pillai, R.S.N., and Murthy K.P., 1973, Arecanut and Species Quarterlty Bulletin, Central Plantation Crops Researh Intitute, Regional Statio, Vittal.

9. Pouchert, C.J., 1978, The Aldrich Library of Infrared Spectra, $2^{\text {nd }}$ Editions, Aldrich Chemical Co.

10. Silverstein, R.M., Bassler, G.C., and Morrill, T.C., 1981, Spectrometric Identification of Organic Compounds, $4^{\text {th }}$ Ed., John Wiley and Sons.

11. Suyani, H., 1991, Kimia dan Sumber Daya Alam, Pusat Penelitian Universitas Andalas, Padang.

12. Whitmore, T.C., 1973, Palm of Malaya, Kuala Lumpur - Singapore - Oxford University Press London.

13. Markam, 1988, Cara Mengidentifikasi Flavonoid, ITB, Bandung. 